\title{
LA DECADENCIA CASTELLANA EN EL FINAL DEL SIGLO XVII A TRAVÉS DE UNA VILLA TERRACAMPINA: VILLAFÁFILA.
}

\author{
MANUEL DE LA GRANJA ALONSO \\ Catedrático.
}

\begin{abstract}
Resumen
Se estudia la decadencia de España en los años finales del siglo XVII tomando como base los aspectos climáticos, económicos, sociales y artísticos deVillafáfila, lugar de Tierra de Campos. Las grandes sequías o abundantes lluvias y malas cosechas ejercieron una influencia importantísima en sus gentes, creando un "fatalismo" que les impedía toda aspiración a una vida mejor. La decadencia local refleja igualmente la sufrida en la Meseta del Duero. La decadencia fue verdaderamente real.
\end{abstract}

\begin{abstract}
Summary
The decline in Spain towards the end of the seventeenth century is studied, using as a base the climatic, economic, social and artistic aspects of Villafáfila, place of "Tierra de Campos". The large droughts or abundant rains and bad crops made an influence of extreme importance in its people, creating a "fatalism" which would not allow them to aspire for a better life.The local decline also reflects the one suffered in the Meseta del Duero. The decline was truly real.
\end{abstract}

\section{Palabras clave}

Carlos II, rey enfermizo, economía maltrecha, enfermedades y pestes, prepotencia del rey de Francia Luis XIV, decadencia de España.

\begin{abstract}
"Cualquiera que haya conocido antes de esta venta (se refiere a la desamortización de tierras baldías y concejiles por Felipe II), a Castilla la Vieja, vería en ella grande e rica población y en las más pobres aldeas de este reyno labradores de a 8 y 9.000 ducados de hacienda y algunos de más, destos hombres ya no se halla ninguno en villas y ciudades, y aquellas ricas fábricas de edificios suntuosos, de alhajadas y bien puestas casas, ya no se ven en ellos más que verdes hiedras y graznantes grajos."2
\end{abstract}

\footnotetext{
${ }^{1}$ G. Barbón Castañeda, "Pobrechosos arbitrios al consumo del vellón y otras razones convenientes al bien y consecuencias de esta Monarquía" B. N. mans. 8.650. 1628.)
} 
Comenzamos este trabajo indicando el resultado final del mismo, la decadencia de Castilla, porque en este tiempo todo le fue adverso: demografía, climatología, malas cosechas, muchas guerras, peor economía, hambre, peste y, por si ello fuese poco, un rey enfermizo e inútil. ${ }^{2}$

En el año de 1665 comenzó a reinar en España Carlos II, el Hechizado. Se le creía poseído de hechizos y brujería dada su endeblez física y mental y su aspecto enfermizo, según nos lo presentan los pintores-retratistas de la época (Juan Carreño de Miranda y Claudio Coello). Nadie hoy acepta tales asertos. Las condiciones personales del rey fueron consecuencia de la consanguinidad de linaje de sus padres, abuelos, bisabuelos y tatarabuelos (su madre era a la vez su prima y su padre su tío). La raza había degenerado. Fue un enfermo potencial desde el momento de la unión sexual de sus padres. Era usual el matrimonio de tíos con sobrinas y viceversa, o primos con primas en idénticas condiciones entre las dos ramas de Habsburgos de España y Austria. El rey tuvo un hermano bastardo, Juan José de Austria, en apariencia de vitalidad normal consecuencia de la rotura de la consanguinidad por la relación entre su padre Felipe IV y una actriz, muy conocida, denominada La Calderona.

\section{CRISIS EUROPEA}

$\mathrm{Al}$ estudiar este reinado hemos de atenernos a los aspectos exteriores e interiores que se sucedieron en el mismo. Los primeros son de tipo político y fundamentalmente fueron guerras con otras naciones europeas. Los segundos tienen que ver con problemas económicos principalmente, originados por las guerras. Según D. Antonio Rodríguez Ortiz: "La España de Carlos II era realmente un país desangrado y empobrecido".

A la endeblez de Carlos II corresponde el poder y fortaleza de Luis XIV de Francia, cuyo objetivo fue la destrucción de los Habsburgo enemigos suyos y de sus antepasados. Aún siendo Carlos II un personaje tímido y pacífico no se vio

\footnotetext{
${ }^{2}$ Duque de Maura: mediocre, casi normal de entendimiento, muy ínfima cultura.

Dr. García Argüelles: hipogenital, intersexual, infantilizado, reacciones hipertímicas eunucoideas, probablemente esteril.

Domínguez Ortiz: incompetente, endeblez de carácter, falta de concentración e irresolución, timidez, desconfianza, débil corporal y espiritualmente, rectitud moral, piedad y fidelidad.
} 
libre de las guerras que le provocaban los reinos europeos, cuyos reyes hasta sortearon (1.668) la posesión del suyo a su muerte.

Flandes siempre fue el motivo de las guerras por las discordias religiosas de los unos y la ambición de los otros. Estas discordias dieron lugar a las "Provincias Obedientes" católicas (la Bélgica actual con sus zonas bien definidas: valona y flamenca) desligadas de las "Provincias Unidas" protestantes (Holanda) y también freno de las apetencias francesas. Al tratado de Aquisgrán (1668) le sucedió el de Nimega (1678), a éste el de Ratisbona (1684), y por último, el de Ryswick (1697). En todas el que perdió fue casi siempre nuestro débil rey. En el primero se perdió la zona flamenca de Lille, próxima a Francia; en el segundo el Franco Condado; en el tercero el Luxemburgo y en el cuarto, aún siendo España la derrotada, se recuperó lo perdido en Flandes y Cataluña por alianza con los vencedores: Inglaterra y Holanda opuestas a las ambiciones del Rey Sol. La realidad de la devolución fue influir en Carlos II para que dejase como heredero de la corona española a Felipe de Anjou, nieto de Luis XIV. Efectivamente, Felipe de Anjou pasará a ser rey de España con el nombre de Felipe V. El enemigo había pasado de los holandeses protestantes a los franceses católicos, de los Orange a Richelieu y Mazarino.

Prácticamente el siglo XVII fue de continuas guerras. En 1640 (anno horribilis) decía el Conde-duque de Olivares: "Pedir a Dios una paz general, que aunque no sea buena ni aún mediana, la tendría por mejor que la más aventajada de las guerras."

La máquina bélica de Luis XIV contrastaba con las estrecheces de la hacienda de Carlos II y con el marasmo y corrupción que imperaba en ella. El déficit crónico de la Hacienda Real alcanzó en la centuria del seiscientos sus cotas más críticas. Un grupo de banqueros portugueses primero y después otro de origen judío, ocuparon el antiguo puesto de los genoveses en el mercado de Amsterdan, adelantando los ducados que necesitaban los ejércitos españoles de Flandes, obteniendo con ello beneficios sustanciosos. Completando el negocio éstos accedieron privilegiadamente a los mercados peninsulares y americanos con sus productos comerciales.

El oro y la plata de las colonias americanas pasaron a las manos de los mercaderes y banqueros, dueños de la economía del reino, y con ello a las potencias extranjeras enemigas. Según el arbitrista Francisco Martínez de la Mata los castellanos eran "míseros sirvientes y pobres recueros de Europa". En el reino sólo circulaba el vellón en continuas emisiones y manipulaciones "baile del vellón", rechazado en las transaciones comerciales extranjeras que sólo admitían la moneda fina. Es el momento de los arbitristas: Celorigo, Fernández 
Navarrete, Sancho de Moncada, etc., y, dentro del reinado, principalmente Ávarez Osorio y Redin, que con sus consejos tratan de poner fin al estado decadente.

\section{CRISIS DEMOGRÁFICA, CLIMÁTICA Y DE PRODUCCIÓN}

Cuanto hemos señalado nos habla de un estado decrépito (1667-1700). Peor aparece cuando nos referimos a los aspectos interiores del mismo. No sucedió por igual en Castilla que en Aragón, por referirnos solamente a los dos reinos peninsulares. La diferncia de leyes y costumbres hizo fracasar la igualdad (Unión de Armas) que quería imponer el Conde-duque de Olivares a los dos reinos. La Corona no poseía un sistema tributario unificado. Era necesario potenciar la autoridad real para enfrentarse a los grandes problemas domésticos e internacionales de la época. Olivares fracasó.

Veamos los aspectos internos que llevaron a Castilla a la decadencia. La diversidad de regiones que tenía hizo que la decadencia en unas fuese más manifiesta que en otras. En la Castilla norteña, en la Tierra de Campos, la decadencia fue verdaderamente real, sus vecinos admitían un fatalismo que les impedía mantener la esperanza de tiempos mejores.

"...sus gentes se acostumbraron a vivir al día y se familiarizaron con los peores desastres que seguidamente se sucedían" , "el pueblo empieza a decaer y los que aún resisten debido a la sucesión de malos resultados y las pesadas cargas que padecen, se hallan descorazonados" (Informe del embajador inglés a su rey).

Últimamente se habla de un comienzo de recuperación al final del reinado, que se manifiesta claramente en el siglo XVIII.

El estudio de esta decadencia es complejo, pues hemos de atenernos a diversos factores sobre demografía, climatología, producción cerealista, precios, y carencia documental, a veces, sobre los mismos. Tampoco están de acuerdo los principales estudiosos en cuándo comienza, cúando termina, y cuál es el momento de mayor hundimiento de la Hacienda Real.Se suele admitir en general entre aquellos que el año 1680 es el momento de mayor depresión en la Castilla del Norte, aunque como dice Antonio Domínguez Ortiz "la llamada recuperación de fin de siglo no es más que una atenuación de estos males". ${ }^{3}$

\footnotetext{
${ }^{3}$ A. Domínguez Ortiz, "La crisis de Castilla en 1677 - 1687" en Crisis y decadencia en la España de los Austrias, 1989, Barcelona, Pag.199.
} 
¿Cuáles son las causas interiores de esta decadencia? Todas van unidas: condiciones climáticas adversas que dan lugar a malas cosechas, incremento de la mortalidad por contagio epidemiológico y elevación de los precios de los productos alimenticios, esencialmente el pan, base de la alimentación en la rural Tierra Campina.; El hambre y las epidemias siempre han ido al mismo ritmo! A ésto hubo que añadir en 1680 una drástica devaluación monetaria, que paralizó toda actividad económica, interrupción del comercio, crisis de las pocas industrias existentes, elevación de salarios y pérdida de brazos productivos. Todo esto originaba en el individuo un derrumbe moral y un terror a morir que le llevaba a prestar atención especial a la religiosidad aumentando los actos piadosos (rogativas, procesiones, misiones, etc.) y morales (regulación del amancebamiento con el matrimonio de los afectados). Este ambiente se pone claramente de manifiesto en las pinturas de Valdés Leal: Triunfo de la muerte y Fin de la Gloria del Mundo del Hospital de la Caridad de Sevilla. ¡Hambre, peste y guerra las tres calamidades que asolaron el mundo!

Los estudios locales son los que con más exactitud pueden llevarnos a la explicación del fenómeno de la decadencia. Nosotros presentamos los correspondientes a Villafáfila, en los límites zamoranos de Tierra de Campos. Estos estudios pueden servirnos de pauta para analizar cualquier otro lugar de esta zona dada la semejanza del terreno, la climatología y la agricultura cerealista.

Se conoce la población de Villafáfila y su tierra por la compra de la Mesa Maestral de la Orden de Santiago (1.541) realizada por el Marqués de Távara, y por el censo sobre el impuesto de "millones" de Felipe II (1.591) y el de Alonso Quintanilla, realizado a principios del siglo XVI, y publicado por Tomás González Censo de Población de las provincias y partidos de la Comarca de Castilla en 1694, 1929, Madrid, corregido por F. Ruiz Martín. ${ }^{4}$

${ }^{4}$ F. Ruiz Martín, "La población española al Comienzo de los Tiempos Modernos", Cuadernos de Historia, Anexos a la revista "Hispania" número 1. 
TABLA 1

\begin{tabular}{|c|c|c|c|c|c|c|}
\hline Villas & Hidalgos \% & Clérigos & $\%$ & Pecheros & $\%$ & Total vecinos \\
\hline Villafáfila & 42 & 13 & & 320 & & 375 \\
\hline San Agustín & 1 & 2 & & & & 53 \\
\hline Revellinos & 5 & 2 & & 108 & & 65 \\
\hline & 9,74 & 17 & 3,45 & 428 & 86,82 & 493 \\
\hline
\end{tabular}

Considerando un coeficiente de 4,5 por vecino, le corresponden 2218 habitantes, cifra bastante aproximada a la realidad de entonces. Ello nos indica que Villafáfila era una de las villas meseteñas realmente importante y notable en cuanto al número de sus hidalgos $(9,7 \%)$. Los pecheros forman la mayor parte del vecindario. Nada se dice de los que no pechaban: pobres y jornaleros. La pobreza total no ha sido frecuente en Tierra de Campos. Hubo otros censos: 1646, por la compra forzosa de juros, y 1691 de reclutamiento militar, que tienen poca consistencia para conocer el cómputo total de habitantes.

El marquesado de Távara, con el señorío de Villafáfila y su Tierra, fue ocupado en el siglo XVII por Enrique Pimentel Enriquez de Guzmán y Moscoso, 5 del título, que compró en 1.653 sus alcabalas por 3.528 .000 mrs. completando totalmente el señorío. Le sucedieron Ana

María Pimentel y Córdoba, Ana María de Córdoba y Pimentel y Francisco de Toledo Córdoba y Pimentel 6, 7 y 8 marqueses de Távara respectivamente.

La Guerra de la Independencia de Portugal terminada en 1668 y la emigración a las Indias (13 emigrantes en el siglo XVI) apenas tuvieron importancia en la decadencia de Villafáfila y su Tierra.

La tabla 2 y el gráfico 1 nos presentan la natalidad y mortalidad de la villa durante el reinado de Carlos II. Se adjunta en los mismos los diezmos que percibió el Monasterio de Moreruela de Granja de Moreruela y Riego del Camino con condiciones edáficas y climáticas muy semejantes a las de Villafáfila.

Para la demografía nos valemos de los libros de bautismo y difuntos del Archivo Parroquial de Villafáfila, publicados por nosotros ${ }^{5}$ y para la producción

\footnotetext{
${ }^{5}$ M. de la Granja Alonso, Villafáfila: Historia y Actualidad de una villa Castellano-Leonesa, 1.996, Zamora.
} 
cerealista y de los diezmos de trigo de Granja de Moreruela y Riego del Camino, de documentos del referido monasterio (AHN. Moreruela. Libro de granos. N 18267) también publicados por nosotros en el indicado libro. Estos últimos no comprenden todo el reinado por comenzar en 1679 y no hay otros documentos. De Villafáfila no existen datos de diezmos en el Archivo Parroquial. ${ }^{6}$

Del examen se deduce un incremento de la mortalidad en tres periodos: 1667-1669 (3 años), 1676-1685 (10 años) y 1698-1700 (3 años) que corresponden a valores de los diezmos bajos o muy bajos: 94 fanegas en 1685, 48 fanegas en 1690 y 39,5 fanegas en 1698. Son periodos de grandes sequías o de lluvias constantes como vamos a indicar.

El año 1666 fue de gran sequía, lo que obligó a que los vecinos de Palencia, con ellos incluimos los de Tierra de Campos, tuvieran que pedir en 12-III-1667 exención fiscal, indicando que a la mala cosecha anterior, el invierno fue muy duro de heladas, con pérdida también de los animales. (AGS. Consejo Juntas de Hacienda. leg. 886). Todo esto dio lugar a una de las mortalidades que tuvieron lugar en la villa durante el reinado, según se puede observar en el gráfico 1. El periodo coincidió con la guerra de Francia, formando España parte de la Coalición con Inglaterra, Holanda y el Imperio Austriaco, contra ella.

El periodo segundo es el más desastroso con que nos encontramos. Los años 1678,1679 y 1680 fueron de malas o deficientes cosechas. En el otoño del último se produjeron lluvias abundantes que causaron los desbordamientos de los rios Pisuerga en Valladolid y Tormes en Salamanca. Esto nos obliga a considerar que ocurriría lo mismo con el Duero en Zamora y con las lagunas en Villafáfila. Hubo rotura de puentes, destrozos en los molinos de sus cauces y ahogamiento de animales, etc., con la imposibilidad de realizar las siembras de la cosecha siguiente. Los años agrícolas 1.680-82 y 1.984-86 fueron de sequía.

La mortalidad fue muy grande, con máximos en los años 1.679, 1682 y sobre todo 1.684. Se decía de este "los ciudadanos caían muertos en las calles y caminos". La primavera fue muy lluviosa y todo en los campos era hierba en vez de trigo.Fue un año de hambre. En 1683 hubo un equilibrio entre la natalidad y la mortalidad, fue de permanentes lluvias. Los años 1.680 y 1.685 son los años de menores cosechas del periodo. En 1682 nos encontramos con alta cosecha, pero con fuerte mortalidad; lo cual se interpreta considerando al habitante con

\footnotetext{
${ }^{6}$ El Monasterio de Moreruela tenía en Villafáfila, en el periodo estudiado, una heredad de tierra cerealista en arrendamiento con una renta anual fija; sus datos no resultan útiles, por no reflejar la variación climática y de producción.
} 
deficiencias biológicas y físicas por las insuficientes cosechas anteriores. El número de muertos del periodo fue de 317 en los 10 años.

Son años hambrunos con desnutrición e incremento de las epidemias. Ante la impotencia para paliar la situación, el creyente acudía a la protección Divina. Así se manifestaba el Concejo de Villafáfila en 1680:

"Por cuanto la falta de agua es grande, que se reconoce la necesidad della en los panes y sembrados desta villa y conviene hacer rogativas a su divina Magestad por intercesión de su Madre, por tanto acordamos se ponga en novena a Nuestra Señora de Villarigo, patrona de la villa, en la iglesia de Santa María del Moral, y para que se traiga y se lleve a su ermita con la decencia debida por cuenta de los propios de la villa!"(Arch. Municipal de Villafáfila. Acuerdo Municipal. 1680). ${ }^{?}$

Dos acontecimientos tuvieron también lugar en 1680 que influyeron notablemente en Castilla: la boda del Rey con la princesa María Luisa de Orleans, que ocasionó gastos extraordinarios de 292.000 escudos de vellón y que recayeron sobre las haciendas de los empobrecidos pecheros; y, la gran devaluación monetaria, que veremos seguidamente. Parte del tiempo de este periodo coincidió con nueva guerra con Francia que terminó con el tratado de Ratisbona e incrementó la decadencia.

En el año 1690 nos encontramos con una baja mortalidad, pero mínima cosecha. En el año 1692 hubo una cosecha escasa, en 1.693 abundante, en el de 1694 escasa, ya que fue un año de sequía, y en el de 1698 la cosecha fue nula. Los años 1697 y 1698 son años de contraste, pues se pasa en un tiempo breve de una máxima natalidad a otra de mayor mortalidad. Hay total coincidencia entre la nula cosecha y la más alta mortalidad en 1698, dentro del tercer periodo. Este año fue un freno a la lenta recuperación. A partir de 1688 durante 9 años tuvo lugar con Francia la guerra de este nombre. Esta se apoderó de Cataluña, tomando incluso Barcelona (1697). La paz de Ryswick puso fín a ella..

En la tabla 3, gráfico 2, representamos los índices de natalidad y mortalidad en medidas quinquenales, tomando como base 100 en el periodo 1671-1675 para todo el tiempo del reinado. La natalidad presenta un ritmo ascendente en general, destacando un máximo intermedio en el periodo de los años 1676-1680. El índice de mortalidad es oscilante con elevados valores entre 1675 y 1685 que

\footnotetext{
${ }^{7}$ Nuestra Señora de Villarigo, también conocida por Nuestra Señora de las Uvas, es una imagen de estilo renacentista del siglo XVI. Esta imagen lleva en sus brazos el Niño con el que comparte un racimo de uvas. Se encuentra en el Museo Parroquial de Villafáfila.
} 
coincide con el máximo de natalidad, lo cual solamente tiene explicación si admitimos una gran mortalidad infantil, corriente en los tiempos que estudiamos. Esto aclara la lenta recuperación que, como venimos diciendo, tuvo lugar al final del siglo XVII.

La tabla 4 y gráfico 3 representa el índice de percepción de diezmos por el Monasterio de Moreruela en medidas biodenales, tomando para todo el tiempo como base 100 el periodo 1684-1686. La tabla y el gráfico nos señalan un profundo descenso del diezmo entre 1684 y 1692 coincidente con el segundo periodo que hemos señalado, periodo que fue de gran mortalidad. A las malas cosechas le sucede un incremento de la mortalidad. Otro descenso menos pronunciado se puede observar entre 1696 y 1698, igualmente coincidente con otra gran mortalidad del tercer periodo.

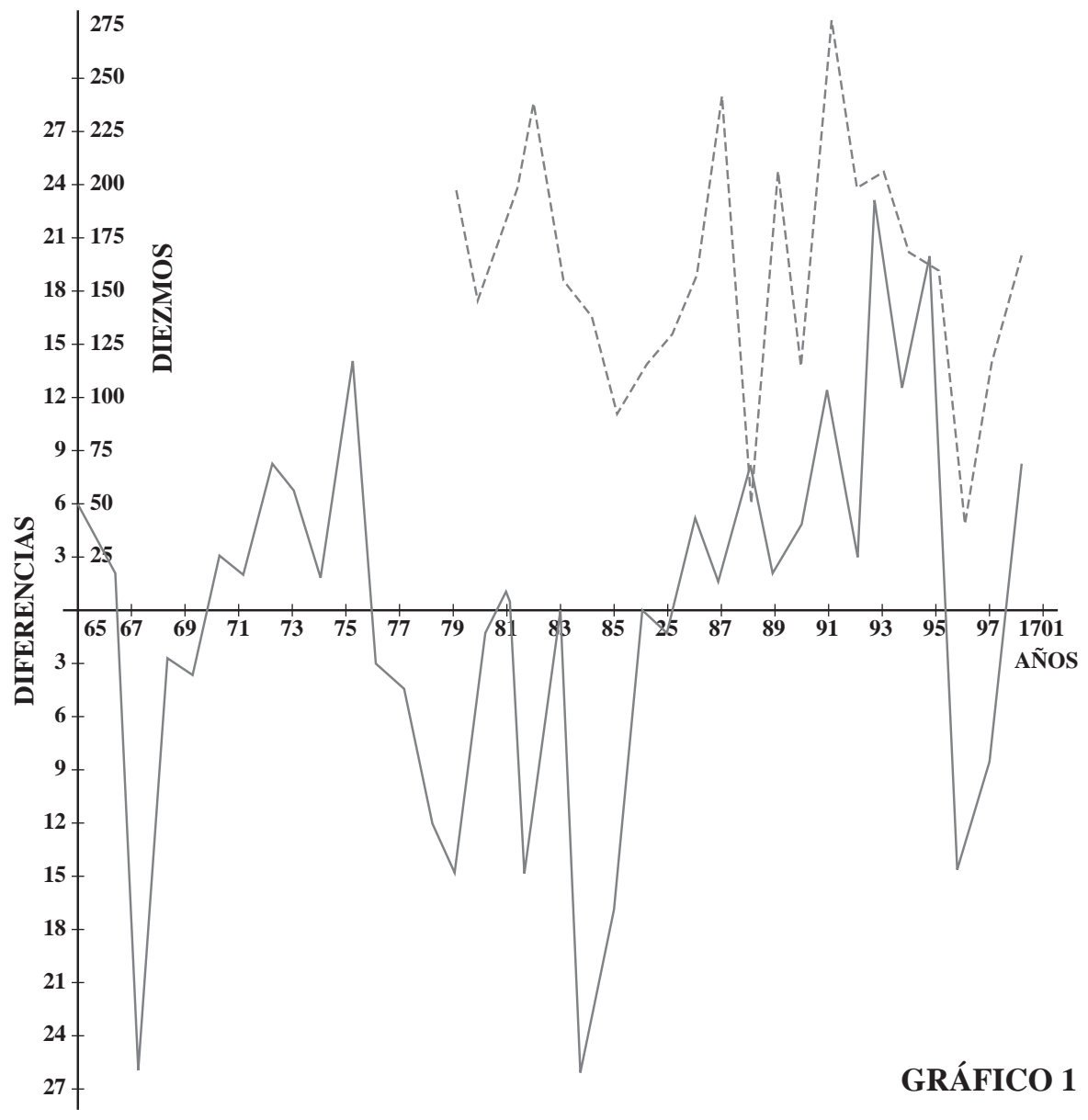


TABLA 2

\begin{tabular}{|c|c|c|c|c|c|c|}
\hline \multirow[t]{2}{*}{ Años } & \multicolumn{3}{|c|}{ Parroquia de Villafáfila } & \multicolumn{3}{|c|}{$\begin{array}{l}\text { Diezmos del Monasterio de } \\
\text { Moreruela en fanegas }\end{array}$} \\
\hline & Bautismos & Difuntos & Diferencia & Granja & Riego & Total \\
\hline 1665 & 14 & 8 & 6 & & & \\
\hline 1666 & 24 & 22 & 2 & & & \\
\hline 1667 & 9 & 35 & -26 & & & \\
\hline 1668 & 12 & 15 & -3 & & & \\
\hline 1669 & 21 & 25 & -4 & & & \\
\hline 1669 & 21 & 18 & 3 & & & \\
\hline 1671 & 17 & 15 & 2 & & & \\
\hline 1672 & 17 & 9 & 8 & & & \\
\hline 1673 & 19 & 12 & 7 & & & \\
\hline 1674 & 16 & 14 & 2 & & & \\
\hline 1675 & 24 & 10 & 14 & & & \\
\hline 1676 & 24 & 27 & -3 & & & \\
\hline 1677 & 30 & 34 & -4 & & & \\
\hline 1678 & 26 & 38 & -12 & & & \\
\hline 1679 & 27 & 41 & -14 & 165 & 34 & 199 \\
\hline 1680 & 28 & 29 & -1 & 125 & 20 & 145 \\
\hline 1681 & 21 & 20 & 1 & 130 & 66 & 196 \\
\hline 1682 & 16 & 30 & -14 & 180 & 55 & 235 \\
\hline 1683 & 22 & 22 & - & 120 & 36 & 156 \\
\hline 1684 & 20 & 46 & -26 & 124 & 12 & 136 \\
\hline 1685 & 13 & 30 & -17 & 78 & 56 & 94 \\
\hline 1686 & 20 & 20 & - & 101 & 18 & 119 \\
\hline 1687 & 13 & 14 & -1 & 114 & 13 & 127 \\
\hline 1688 & 22 & 17 & 5 & 142 & 14 & 156 \\
\hline 1689 & 25 & 23 & 2 & 202 & 37 & 239 \\
\hline 1690 & 25 & 17 & 8 & 41 & 7 & 48 \\
\hline 1691 & 19 & 15 & 4 & 132 & 78 & 210 \\
\hline 1692 & 14 & 9 & 5 & 111 & 8 & 119 \\
\hline 1693 & 26 & 13 & 13 & 186 & 83 & 269 \\
\hline 1694 & 18 & 15 & 3 & 140 & 55 & 195 \\
\hline 1695 & 33 & 10 & 23 & 156 & 42 & 198 \\
\hline 1696 & 22 & 13 & 9 & 150 & 23 & 173 \\
\hline 1697 & 26 & 6 & 20 & 142 & 23 & 165 \\
\hline 1698 & 22 & 36 & -14 & 36 & 5,5 & 39,5 \\
\hline 1699 & 21 & 30 & -9 & 114 & 3 & 117 \\
\hline 1700 & 29 & 21 & 8 & 151 & 2,5 & 153,5 \\
\hline
\end{tabular}




\section{TABLA 3}

\begin{tabular}{ccccc}
\hline Años & $N^{o}$ de bautizos quinquenales & Índices & $N^{\circ}$ de defunciones quinquenales & Índices \\
$1.666-1670$ & 87 & 94 & 115 & 192 \\
$1671-1675$ & 93 & 100 & 60 & 100 \\
$1676-1680$ & 135 & 146 & 169 & 282 \\
$1681-1685$ & 92 & 99 & 148 & 247 \\
$1686-1690$ & 105 & 113 & 91 & 152 \\
$1691-1695$ & 110 & 119 & 62 & 104 \\
$1696-1700$ & 120 & 130 & 106 & 177 \\
& & & & \\
\hline
\end{tabular}

\section{GRÁFICO 2}
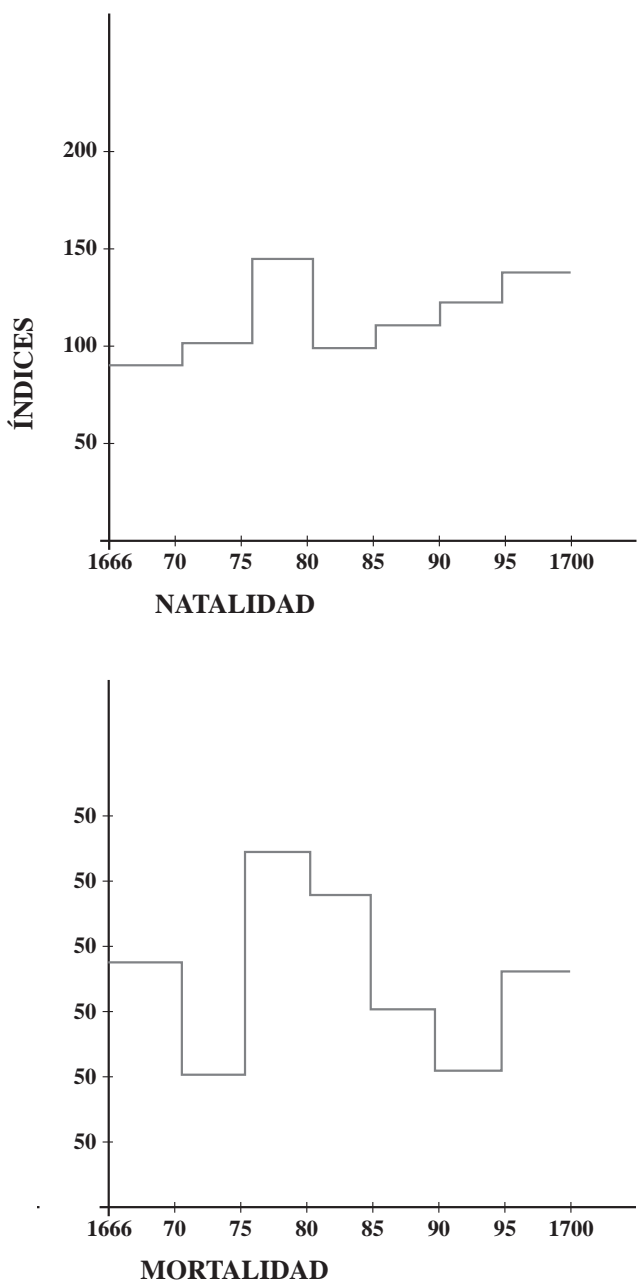


\section{TABLA 4}

$\begin{array}{ccc}\text { Año } & \text { Fanegas } & \text { Índice } \\ 1678-1680 & 344 & 162 \\ 1680-1682 & 431 & 203 \\ 1682-1684 & 392 & 184 \\ 1684-1686 & 213 & 100 \\ 1686-1688 & 283 & 133 \\ 1688-1690 & 287 & 135 \\ 1690-1692 & 329 & 155 \\ 1692-1694 & 464 & 218 \\ 1694-1696 & 371 & 174 \\ 1696-1698 & 205 & 96 \\ 1698-1700 & 27 & 127\end{array}$

\section{GRÁFICO 3}

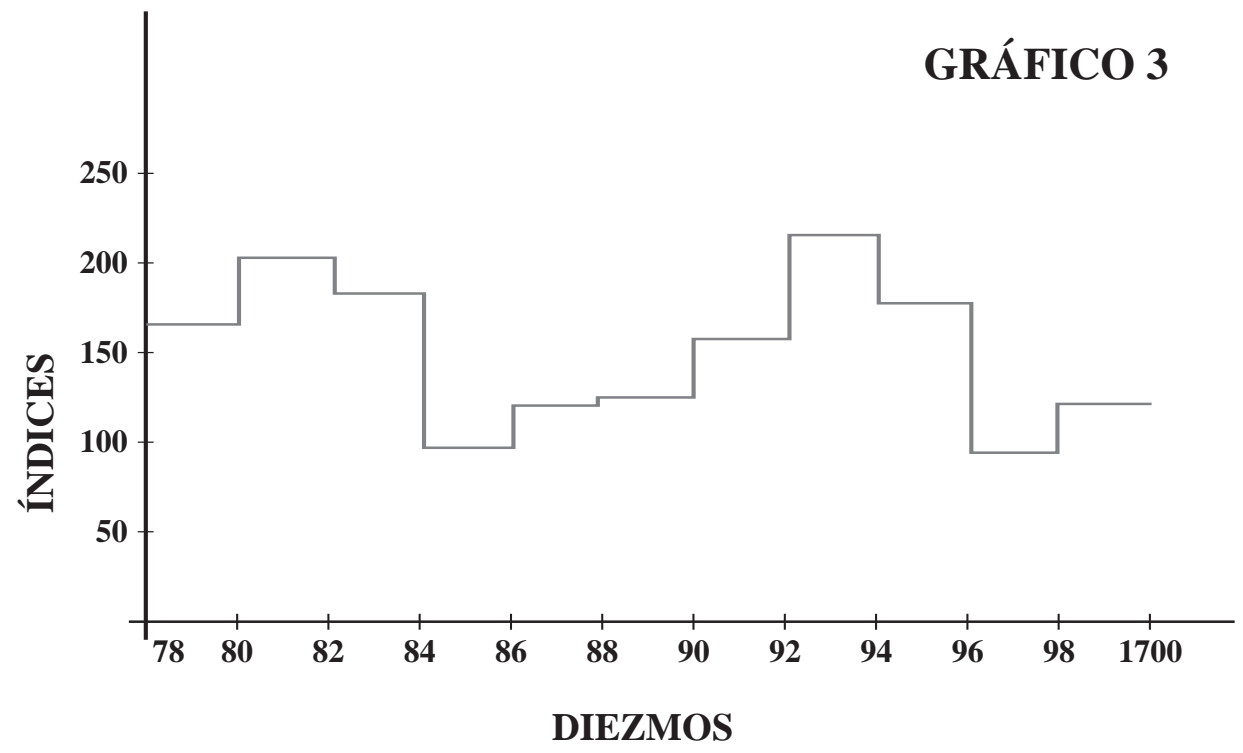


Las fiebres tercianas, los catarros, los tabardillos y principalmente el tifus fueron los causantes de las mayores mortalidades en los periodos señalados. Los documentos los denominan como "epidemia general de enfermedades"ytambién "corrupción del aire"s. Las tercianas siempre fueron endémicas en Villafáfila a consecuencia de sus lagunas.

La falta de alimentación debido a una mala cosecha, producía el agravamiento de la peste. Los organismos desnutridos han sido siempre presa de enfermedades contagiosas, que la medicida de entonces era incapaz de atajar. El problema terminaba con la muerte y enterramiento del apestado (el último tenía lugar en las iglesias contribuyendo a la propagación de las epidemias). Había que deshacerse de todos los objetos que hubieran estado en contacto con el enfermo: ropas, utensilios y demas enseres, todos debían quemarse, con lo que la vida de los supervivientes resultaba totalmente trastornada.

Lo que sucedía con las personas ocurría igualmente con los animales. La yuntas de labores del terrazo se perdían, con lo cual este resultaba más improductivo. Por otra parte se empleaban semillas de bajo rendimiento: candeal y truchal. Se conocen datos del Monasterio de Matallana (Valladolid) con unos rendimientos en el año 1680 de 3,7 fanegas para el trigo y 5,3 para la cebada.

Todo esto contribuía a la despoblación como sucedió en Otero de Sariegos (en la actualidad perteneciente al Ayuntamiento de Villafáfila y a solo dos kilómetros de distancia) donde los vecinos pidieron y obtuvieron rebaja de las cantidades del "encabezamiento" en el trienio 1691-1694 de los servicios ordinarios y extraordinarios de alcabalas y otros tributos. "Otero de Siriego dio memorial en 1.681 diciendo que en 1665 se despobló, sus doce vecinos se fueron a vivir a otros lugares y su iglesia se quedó demolida y ahora a instancia del condestable (Bernardino Fernández de Velasco), cuya es la villa, han vuelto a ella seis vecinos. Se le concedió exención de tributos por diez años"9

El sistema fiscal acelerá el despoblamiento de Castilla. Este temporalmente fue también una práctica usada por los campesinos para escapar de las deudas e impuestos.

El minifundismo del terreno fue patrimonio de Villafáfila hasta mediados del siglo XX. El patrimonio de la Iglesia creció, en virtud de las donaciones de los fieles, hasta superar el 50\% del terrazo municipal, según muestra el Catastro del Marqués de la Ensenada en el siglo XVIII. Los grandes propietarios de la

\footnotetext{
${ }^{8}$ V. Pérez Moreda, La crisis de mortalidad en la España Interior. Siglos XIV - XIX, 1980, Madrid

${ }^{9}$ AGS. Consejo Juntas Hacienda. leg 1445.
} 
tierra eran los monasterios de Moreruela, Santispíritus, Bernardas y Santo Domingo de Benavente, Santa Sofía de Toro, San Marcos de León y las cofradías y capellanías locales. Sus arrendatarios eran los campesinos y algunos hidalgos o descendientes de estos, según se desprende del catastro indicado. La venta de tierras marginales y baldías en tiempos de Felipe II tuvo notable influencia. Esta ascendió a 2.262 fanegas, que antes cultivaban modestos agricultores sin abono de rentas.

El propio municipio de Villafáfila estaba endeudado. Tenía un censo a su cargo de 12.000 reales de vellón de principal con unos réditos anuales de 360 a favor de D. Joaquín Vicente Carrillo, vecino y regidor de Palencia, según refleja el catastro citado anteriormente. Era suficiente que sucedieran unos años de malas cosechas para que los pueblos cayeran en manos de los prestamistas.

El beneficio de la Mesta, frente a los campesinos locales, no tuvo gran trascendencia en la villa. Villafáfila fue lugar de paso según lo evidencian las vias del "Cordel de las Merinas" y la "Vereda de Toro" de su término. Su ganadería fue siempre estante, según la abundancia de prados comunales que han llegado hasta nosotros. Su lana suponemos pasaría a Palencia por ser el único lugar con producción textil en Tierra de Campos en aquellos tiempos.

De lo expuesto concluímos que, la mayor parte de los años, el grano cosechado no llegaría para la siembra del año siguiente. Había que pagar diezmos, impuestos (alcabalas, millones y unos por ciento) y arrendamientos (en opinión de Celorigo superaban el diezmo), con lo que nada quedaba para la alimentación familiar y con ello se sucedían los años de hambre. Economías de mera supervivencia. El campesino perecía o buscaba nuevos recursos no siempre alcanzables: cultivo personal del viñedo, crianza de animales (ovejas, cerdos, gallinas, etc.) no siempre posible por falta de cosecha cerealera (cereales pienso, diríamos ahora) u otras ocupaciones siempre difíciles. Muchas veces era obligada la emigración a las ciudades y pueblos importantes, con incremento del vagabundeo en estas. Era mejor vivir de la caridad, "pobres de solemnidad". También la tentativa de la superación obligaba al campesino a caer en manos del prestamista. $^{10}$

El campesino era vulnerable cuando se producían variaciones demográficas, climáticas o especulativas y, como veremos seguidamente, cuando tenían lugar

${ }^{10} \mathrm{~B}$. Bennassar, Valladolid au siecle d'or. Une ville de Castilla et sa campagne au XVI siegle, 1967, París. 
variaciones en los precios de los productos que vendía o surgían las crisis económicas del reino. El precio de los cereales corría pareja con la abundancia o escasez de cosecha. En el primer caso bajaba y en el segundo subía. Esto no impedía que los rentistas, acaparadores, diezmeros, mercaderes, etc., sacasen los productos comerciables al mercado, cuando la coyuntura les fuese favorable. La comercialización del cereal dependía de ellos en gran parte, si bien los pósitos o alhóndigas paliaron a veces la situación.

En la comercialización del trigo de diezmos del Monasterio de Moreruela vamos a considerar el mercado de Zamora, por razones de proximidad y venta del trigo diezmal de su catedral ${ }^{11}$ Tabla $5^{12}$. Apenas se conocen datos de precios comerciales en Castilla en los tiempos que estudiamos. Gonzalo Anes Álvarez lo hizo en tierras de Segovia. ${ }^{13}$

La mala cosecha de 1.683 obligó a que el pan de dos libras se vendiese en el mercado ferial de Medina de Rioseco a 6-7 cuartos (AHN. Consejos leg. 7195). Es un dato de los momentos de penuria.

Para contabilizar la venta del trigo morerolense hemos de atenernos no solo a la comercialización de cada año, también a la efectuada a lo largo de cada uno de ellos. La venta se hacía preferentemente en los "meses mayores" (marzo a junio) por ser cuando el grano tenía más valor. Hubo años hambrunos y posiblemente tasados que se vendió en los meses invernales. Igualmente por razones de almacenamiento insuficiente, ante cosechas previsiblemente abundantes, se anticipó la venta. También se especulaba y por ello cuando se preveía bajaba el precio del trigo por razones de tasa, se adquirían censos, por ser obligada la venta de aquel.

Los precios del trigo variaban de acuerdo con las circunstancias anuales. Estaba tasado en 18 reales por fanega y año, pero solo tenía efectividad en los años de penuria por imposición real puesto que en los demás años el valor era superior. El precio que consignamos no es el verdadero cotizado en el mercado (el mercurial), sino el que exigía o convenía el Cabildo de Zamora con el

11 J.A. Álvarez Vázquez, Rentas, precios y créditos en Zamora en el Antiguo Régimen. H1987, Zamora.

${ }^{12}$ El Monasterio de Moreruela anualmente vendía sus excedentes de trigo en condiciones semejantes a las de la Catedral de Zamora y por ello hemos aceptado los precios de ésta.

${ }^{13}$ G. Anes Álvarez, "Crisis del siglo XVII: producción agrícola, precios e ingresos en tierras de Segovia", Moneda y Crédito. 1965. 
comprador. Es el "precio de mercado", siguiendo a José Antonio Álvarez en el trabajo anteriormente indicado, de la Tabla 5.

Lógicamente los años de mayor venta -no de mayor cosecha- corresponden a los de mayor precio y los de menor venta al contrario. En el primero se vacían las paneras, en las cuales hubo veces que el atrojamiento del grano se mantuvo hasta seis años, esperando la coyuntura favorable de venta.

\section{TABLA 5}

\begin{tabular}{|c|c|c|c|}
\hline Años & $\begin{array}{c}\text { Diezmos } \\
\text { Fanegas }\end{array}$ & $\begin{array}{c}\text { Precio de la fanega } \\
\text { en reales }\end{array}$ & $\begin{array}{c}\text { Ingresos totales } \\
\text { en reales }\end{array}$ \\
\hline 1679 & 199 & 26 & 5174 \\
1680 & 145 & 26 & 3770 \\
1681 & 196 & 17 & 3332 \\
1682 & 235 & 6 & 1410 \\
1683 & 156 & 18 & 2808 \\
1684 & 136 & 21 & 2856 \\
1685 & 94 & 22 & 2068 \\
1686 & 119 & 14 & 1666 \\
1687 & 127 & 14 & 1778 \\
1688 & 156 & 9 & 1404 \\
1689 & 239 & 7 & 1673 \\
1690 & 48 & 18 & 864 \\
1691 & 210 & 13,5 & 2520 \\
1692 & 119 & 18 & 2142 \\
1693 & 269 & 18 & 4842 \\
1694 & 195 & 14 & 2730 \\
1695 & 198 & 9,5 & 1881 \\
1696 & 173 & 8,5 & 1470 \\
1697 & 165 & 10 & 1320 \\
1698 & 39,5 & 22 & 869 \\
1699 & 117 & 23 & 2691 \\
1700 & 153,5 & 28 & 4298 \\
& & & \\
\hline
\end{tabular}


El periodo primero que hemos estudiado en la demografía, (1666-1669) fue de precio alto, $26 \mathrm{rls} /$ fanega, por coincidir con pobres cosechas. Transcurrido 1670 comienza un periodo de bajos precios, 7,5 rls. en 1673 en Toro, para vender el grano atrojado y añejo que se había guardado con anterioridad. El bajo precio hizo fácil la venta a muchos compradores de otras zonas. La inflación y las malas cosechas son las responsables de la subida de los precios a 23 rls en 1676. Años de epidemias y hambres. Ante esta situación, el corregidor de Zamora, por ejemplo, para poder abastecer la ciudad embargó los granos, con la oposición del Cabildo de su Catedral. Este, juntamente con otros eclesiásticos, acudieron al rey, pero éste nada resolvió hasta 1680 autorizando la venta a "precio moderado" respecto del "bajo valor de la moneda de vellón circulante". No hubo moderación, pues el precio cotizado de 26 rls fue uno de los más altos del periodo.

Desde el año 1680, con su crisis monetaria, hasta 1686 subieron los precios (a 22 rls en 1685) por las malas cosechas y grandes mortandades (en 1683 se tasó a 18 rls). La venta fue a lo largo del año, para ir luchando contra tanta miseria. La situación era tan crítica que el Cabildo de Zamora en lugar de recibir diezmos (igual sucedía en Moreruela) los entregaba a sus diocesanos, 48 fanegas a vecinos de San Román del Hornija y 800 a los de Zamora para paliar el hambre. En 1687 ante una buena cosecha el precio bajó a 14 rls. y los años 1688 y 1689 al ser de notables cosechas el precio aún bajó más acercándose a 7 rls.

La malísima cosecha de 1690 provocó la subida de los precios y volvió la tasa. En 1695 bajaron a 9,5 rls. La mala cosecha de 1698 hace que suban los precios hasta 22 rls, por ello una orden real ordenó que no se pagase a más de 28 rls que superaba la tasa y esta orden nadie la respetó. La Pragmática de 1699 reconoció los privilegios de los eclesiásticos y estableció nueva tasa.

Al comparar los precios del mercado de Zamora con los, del mercado de Segovia (mercuriales) indicados en el trabajo de Anes González se observa un valor superior del precio de éste respecto a aquel, pero siguen ambos una variación semejante de alzas y bajas, lo que en cierto modo nos prueba que en general, dentro de Castilla la Vieja, las condiciones climáticas y los niveles de vida fueron bastante semejantes.

El importe dinerario percibido por el Monasterio de Moreruela tomó valores notables excepto en los años 1682, 1690 y 1698, años que corresponden a pobres o nulas cosechas. 


\section{CRISIS MONETARIA}

A la crisis ocasionada por las guerra, las mortalidades y las malas cosechas vino a sumarse la reforma monetaria de 1680 del "primer ministro" Duque de Medinaceli, que pretendía sacar al Reino de la crisis endémica que sufría. A. Somoza Quiroga dice refiriéndose al sistema fiscal castellano: "era tan complicado y tenía tantos impuestos que ni el Consejo de Hacienda los entiende, ni los vasallos saben lo que deben pagar".

En 1666 el Consejo de Hacienda reconocía que la razón principal de la pobreza se encontraba en el exceso de impuestos con que estaba grabado el Reino. (AGS.Consejo J. Hacienda leg. 885). Entre 1580 y 1680 se había incrementado estos en un $400 \%$ y los precios en un $300 \%$.

La reforma consistió en la acuñación de moneda de vellón denominada de Molinos. Su valor verdadero era inferior al nominal, lo que originó una enorme inflación, obligando a dar a la moneda de plata un sobreprecio -premio de la plata- que llegó hasta el $50 \%$ de su valor. Esto originó un verdadero caos económico en Castilla. Fue una verdadera falsificación menotaria, pues cada marco de Molinos tenía 4 ochavas de plata por 7 onzas y 3 ochavas de cobre. Su valor era de 24 reales de curso legal, aunque el suyo según la composición no llegaba a 10 reales.Esto suponía para la Hacienda Real un notable beneficio.

Los falsificadores de moneda lanzaron al mercado moneda de peor calidad y con ello se llegó al descrédito total de la de Molinos. Había al mismo tiempo tres clases de moneda en circulación: moneda de plata sobrevalorada, de los Molinos y de vellón (solo cobre). La última fue preferida a la anterior para saldar la Deuda Pública pues se devaluó a la cuarta parte de su valor nominal, mientras la de Molinos lo hizo en la octava del suyo. Era "el baile del vellón" como corrientemente se le designa. La revalorización de la moneda de plata fue enorme. Según E. J. Hamilton en War and princes Spain 1651-1800 la revalorización fue del $90 \%$ en 1675 para subir al $275 \%$ en $1.680 .{ }^{14}$

Esta situación creada por la Hacienda Real era gravísima, ya que los impuestos los percibía en moneda de Molinos, mientras que los gastos exteriores (guerra de Europa e importaciones) eran abonados en moneda de plata. La

${ }^{14}$ A. Domínguez Ortiz, Política fiscal y cambio social en la España del siglo XVII, 1941, Madrid, Pag 164. 
inflación ocasionada resultó mucho peor que el beneficio obtenido. La consecuencia fue una fuerte subida de los precios, especialmente de los productos alimenticios, lo que unido a las malas cosechas trajo como consecuencia el incremento de la mortalidad y la ruina de los vecinos rurales principalmente.

Las monedas de oro y plata fueron retraídas por los particulares y por la propia Hacienda, lo que ocasionó un marasmo que, en algunos sectores comerciales, llevó a la total paralización, llegándose al trueque de productos. (AGS. Consejo J. Hacienda. leg. 1425). Los precios continuaron subiendo y no hubo más remedio que implantar tasas. Para solucionar la situación se amonedó la plata que llegó de América e incluso se adquirieron objetos de plata a particulares; igual se hizo con el cobre, que se pagaba a 3,5 rls el marco para incrementar el mismo en el vellón a 6 reales.

La economía castellana se paralizó: los caldereros por falta de cobre, los gremios por la tasa impuesta y los campesinos por los bajos precios de los productos. Todo degeneró en una crisis y no hubo más remedio que condonar impuestos, como hemos visto en Otero de Sariegos, como consecuencia de la miseria y despoblación del agro castellano.

A continuación presentamos el Presupuesto de Gastos del Reino para el año de 1680 que demuestra el caos existente. Este presupuesto constaba de gastos fijos e ingresos disponibles. Los primeros correspondían a gastos exteriores al reino (pagados en plata) por importe de 3.427 .400 escudos y otros interiores (pagados en vellón) de 6.048.780 escudos. Al transformar los primeros en vellón el total pasaba a 18.044.680 escudos de vellón. Los gastos de administración subieron a 1.804.468 escudos. El total del presupuesto, todo en vellón, alcanzaba los 19.849 .148 escudos.

Los segundos, corresponden a 376.797 escudos en plata americana que transformados en vellón ascienden a 1.291.471 escudos, y otros en vellón de procedencia interior ( media annata de juros, deducción de pensiones, del Consejo de Indias, del arriendo de impuestos y sus arrendadores, impuestos sobre nombramientos, títulos y mercedes, votado por el gremio de posaderos de Madrid para la boda real y para lanzas) 8.208.000 escudos y en total 9.499.471 escudos de vellón. Considerando todos los gastos 29.348.619 escudos y como los ingresos presupuestados fueron 8.998 .942 escudos, corresponde a los primeros un superabit de 10.349.677 escudos de vellón. Lógicamente, esto suponía que muchas deudas se originarían desde el principio del año por falta de pago. El verdadero déficit presupuestario de ingresos resultaba del gasto 
extraordinario de las guerras, embajadores exteriores y gastos suntuarios de la Corte que superaban los 3 millones de escudos en plata ${ }^{15}$. Del incremento de gastos palatinos dice Antonio Domínguez Ortiz: "Extravagante derroche en una nación empobrecida"1"

Lo difícil entonces era conseguir la plata. La procedente de América, antes de llegar a Sevilla, ya estaba asignada a los banqueros y mercaderes para pagar los adelantos que estos habían realizado para los gastos de guerra y Casas Reales. Inclusive se llegó a tomar la plata que venía nominada a los particulares (1691) a los que se les entregaban juros como pago de deuda. Hubo momentos en que los banqueros se negaron a realizar préstamos por falta de seguridad a la hora de recibir los pagos de la Hacienda.

El hambre y los robos surgieron por todas partes. Los comerciantes y banqueros fueron los más perjudicados en la devaluación de 1680. Algunos de éstos de Medina de Rioseco se arruinaron y abandonaron sus negocios. Las pérdidas que sufrió el fisco por impago de impuestos fueron muy grandes, los eclesiásticos no percibíeron los diezmos, ni los rentistas las rentas.

Ante esta situación los Consejeros de Hacienda propusieron al Rey remedios para que circulasen los Molinos y mejorase la Hacienda ${ }^{17}$. Las soluciones fueron muy dispares y curiosas: El consejero Alonso Martínez de Prado propuso acuñar moneda en la proporción de tres millones de plata por medio de vellón. Gil de Castejón consideraba que el problema no era de acuñación, sino de tipo personal y proponía tomar media annata de las alcabalas enajenadas por la Corona, pedir un millón a los que habían comprado oficios públicos, que los dirigentes de las guerras pagasen estas, que se continuase la venta de villas y baldíos como había sucedido en los tiempos de Felipe II y que se tomase la nómina de los ministros y miembros de los Consejos que gobernaban el Reino.

Esto en parte se cumplió, ya que se vendieron títulos nobiliarios, tierras de realengo y baldíos y se enajenaron cargos públicos en algunos ayuntamientos.

\footnotetext{
${ }^{15}$ H. Kamen, La España de Carlos II, 1981, Barcelona, pag.567.

${ }^{16}$ A. Domíguez Ortiz, "Los gastos de la Corte de España en el sigloXVII" en Crisis y decadencia de la España de los Austrias. Pag 89.

${ }^{17}$ Los Consejos eran cuerpos consultivos que proponían al rey las soluciones que creían más convenientes, pero que no siempre se llevaban a efecto, porque los íntimos del rey eran los que decidían en muchas ocasiones(discrepancias, por ejemplo, entre la reina madre y el hermano bastardo Juan José de Austria.
} 
Conseguir un título nobiliario era dar un paso para acercarse a la realeza y lograr cargos burocráticos bien remunerados. Los compradores de baldíos formaron una burguesía rural que se adueñó de los organismos municipales para su beneficio.

Para el consejero Alonso de Olea la falta de moneda en circulación se debía a las importaciones de mercancias extranjeras: pinturas, tapices, plata labrada, tejidos, etc.

"De todo el daño que se padece tienen la culpa, por lo que toca a esta Corte, los mercaderes de la puerta de Guadalaxara, Santa Cruz y Calle Mayor convidando con ellas a los que no se acuerdan ni llevan ánimo de comprarlas".

Se incluía también a los alcaldes de sacas (aduaneros diríamos hoy) y embajadores que cooperaban en la saca monetaria de los comerciantes. La situación del campesino, pequeño propietario o jornalero era calamitosa, especialmente en los años de malas cosechas que como hemos visto eran los que se daban con más frecuencia. Existía un enorme contraste entre la riqueza de los unos y la pobreza de los otros.

En 1683, se estableció una Junta de Medios para realizar una reforma fiscal; se sustituyó el sistema de arriendo por el de encabezamiento, con la finalidad de llegar a una verdadera tasa de tributación. Los ingresos fueron menores porque incluían condonaciones de impuestos ello hubo de renunciarse en parte al nuevo sistema fiscal. Los juros ascendieron a un valor que se llevaba la mayor parte de los ingresos, no obstante el descuento que sobre ellos se hacía. Había orden del rey de austeridad, lo mismo sucedería en 1686, pero no hubo efectividad por concesión de peticiones y mercedes.

Todo seguía mal. En 1684 se propuso el rey que se rehabilitase la moneda de Molinos y se labrasen reales sencillos y dobles con la plata americana. "El rey aceptó y encargó que se hiciesen oraciones y rogativas para impetrar del cielo el acierto en tan graves circunstancias" ${ }^{18}$. Los castellanos siempre rogantes de la voluntad Divina, pero sin poner remedio verdadero a la situación del reino.

En 1686, el Conde de Oropesa, que tenía el cargo de primer ministro, manda suspender los pagos, excepto los "asientos" y gastos de guerra. Se efectuó una devaluación de la moneda de plata en un quinto y se evitó, en lo posible, que fuera a parar al extranjero; su precio se redujo al $50 \%$. La devaluación, aún

${ }^{18}$ A. Domínguez Ortiz, Crisis y decadencia de Castilla en 1.677-1.687. Pag. 214. 
siendo una medida inflacionista, fue justificada, puesto que ponía término a un largo periodo de inestabilidad monetaria. La plata escondida salió al mercado, los precios se estabilizaron y se inició una modesta recuperación económica a partir de 1687. Años verdaderamente trágicos como habían sido los anteriores, no se repitieron tanto.

En este mismo año 1686, las rentas de Castilla ascendieron a 8.409.779 escudos de vellón, pero los juros que gravaban estas rentas necesitaban más de 12.297157. La situación era deficitaria. Se tomaron 4 millones de ducados de los ingresos para el funcionamiento mínimo de la "causa pública", y el resto se distribuyó entre los acreedores de juros. Había un enorme contraste entre la opulencia de la Corte y la miseria del pueblo castellano. Se creó la Superintendencia de Hacienda encomendada al Marqués de los Vélez. Se consiguió reducir el déficit y se logró la implanteción de una justicia social en los impuestos locales de carne, vino y aceite. Se sustituyeron los arrendamientos por el encabezamiento acorde con los municipios, pero todo fracasó por causa de las oligarquías locales y se volvió a los arrendamientos. Se intentó conseguir un ahorro mensual de 15.000 escudos en la despensa real, pero nada se pudo lograr a causa del número de personas que tenían derecho a ella.

Estos fracasos no fueron totalmente inútiles, ya que mediante las reformas se logró conocer la efectiva y verdadera situación de la carga fiscal. No se crearon nuevos impuestos, lo que fue verdaderamente importante, y se suprimieron algunos, se condonaron deudas y se redujeron las rentas reales. Para conseguir ésto y estabilizar la Hacienda se incrementó la venta de títulos nobiliarios. Se pretendió así pagar con "honras" a los beneméritos, que pagaban rentas en lugar de pedirlas. Era una forma de obtener ingresos extraordinarios sin gravar a los pecheros.

Con éstos y otros remedios, más o menos carentes de realidad, se terminó el siglo XVII. Con el comienzo del siglo XVIII llegó la nueva dinastía Borbónica con la que mejoraron las condiciones de la Hacienda Real y la vida de los castellanos.

La última década del siglo XVII es considerada por algunos historiadores como época de renovación y reconstrucción de Castilla, tanto desde el punto de vista económico como demográfico. Según Domínguez Ortiz : "Era el crecimiento de un estado que reposaba sobre una infraestructura económica demasiado débil para la carga que se hizo gravitar sobre ella, pero esta carga fue sobre todo militar ${ }^{19}$. La inflación con más gastos que ingresos fue la causa

\footnotetext{
${ }^{19}$ A. Domínguez Ortiz, Los gastos de la Corte de España en el siglo XVII . pag. 96.
} 
principal de la decadencia. Para Jorge Nadal las causas de la decadencia estuvieron en la "peste económica" más que en la peste real, en las "enfermedades sociales" más que en las epidemias ${ }^{20}$.

\section{INFLUENCIA ARTÍSTICA}

Quien haya leído las páginas anteriores se preguntará. ¿Qué interés artístico puede haber en una sociedad y en una región empobrecida y diezmada por el hambre y las epidemias? La historia de España nos dice que no hubo mucha coincidencia entre la prosperidad o decadencia económica y el esplendor cultural. Al siglo XVII, decadente económicamente, corresponde un Siglo de Oro literario y artístico: Cervantes, Lope de Vega, Calderón y otros escritores; Velázquez, Murillo, Gregorio Fernández, Alonso Cano y otros artistas.Todos ellos son personajes cumbres que en algún momento de su vida tuvieron que ver con las letras y las artes castellanas.

En una sociedad en general empobrecida, la Iglesia continuaba siendo rica por las continuas donaciones de los cristianos. Se viven los años de la Contrarreforma que tienen a la imagen como intercesora y como verdadera representación del personaje a quien dirigir la plegaria. En la lucha contra el Protestantismo el arte del siglo XVII se convierte en un arte eminentemente religioso.

Resulta difícil comprender que en Villafáfila, agobiada por las dificultades, la penuria y el hambre, puedan encontrarse obras artísticas de primer orden en el campo de la escultura como las que se conservan del siglo del Barroco. Gómez Moreno dijo: "El arte se nutre del despilfarro", refiriéndose a los gastos que la Corte, la nobleza y la burguesía adinerada hacían preferentemente en el extranjero. El pueblo encontraba en la religión el consuelo a las angustias que la pobreza le producía y se integraba en las cofradías de los gremios, cuyas iglesias eran los principales clientes de pintores y escultores. Contrastando con la calamitosa situación económica, las iglesias se llenaron de retablos dorados, repletos de imágenes, muchas de ellas procesionales, que dirigían y orientan las devociones y a veces la vida de las gentes.

Villafáfila, ayer como hoy, vive las escenas de la pasión de Cristo en su Semana Santa como si directamente interviniese en ellas. En la madrugada del Viernes Santo, al desfilar las imágenes barrocas de Jesús Nazareno, la Virgen y

\footnotetext{
${ }^{20}$ J. Nadal, La población española. Siglos XVI-XX, 1.966, Barcelona.
} 
San Juan, el Camino del Calvario se traslada a su Plaza Mayor donde tiene lugar el "encuentro". El momento más típico y emocionante llega cuando el orador sagrado que dirije la escena grita: "corre Juan a ver a María" y los asistentes corean: "que te está esperando a la puerta del tío Chavarría" (personaje que se hizo popular por la situación de su casa) y el apostol se apresura a informar a la Virgen de lo que acontece a su Hijo. Momentos después tiene lugar el "encuentro" de María y Cristo para seguir caminando unidos hasta el lugar donde tras la crucifixión se va a producir la muerte de Jesucristo.

Villafáfila fue siempre una villa muy religiosa, así nos lo evidencian sus siete iglesias e igual número de ermitas documentadas. Desgraciadamente, el paso del tiempo, la endeble construcción mudejar de estos edificios, la desidia y la indiferencia han hecho que desaparezcan todos estas y sólo se haya conservado la de Santa María del Moral, notable iglesia de estilo góticomudejar $^{21}$. De sus cuatro retablos barrocos sobredorados tres son prechurriguerescos y se atribuyen al escultor Francisco Diez de Benavente; el cuarto, de autor desconocido, responde al tipo de retablo con cascarón de Tomás Sierra que se conserva en la Iglesia de Santiago de Medina de Rioseco ${ }^{22}$.

La imaginería es notable y numerosa, se conservan 38 imágenes de las que 21 son barrocas. Se encuentran distribuidas entre la Iglesia y el Museo Parroquial. También hay cuatro candeleros barrocos representativos de la Virgen. Entre las esculturas es necesario destacar las de Jesús, cargado con la cruz a cuestas; el Nazareno que procesiona el día del "encuentro"; Jesús Yacente, obra en la que el escultor ha seguido los pasos de Gregorio Fernández; y el Salvador con la bola del mundo El tesoro escultórico de Villafáfila cuenta también con dos Inmaculadas, una de ellas con la inscripción "Nuestra Señora dla Cosolazio" que recuerda a Juan de Juni. Estas obras están documentadas, pero se desconoce su autor por no figurar en los libros parroquiales. Algunas imágenes llevan el nombre del donante como ocurre con la de Santa Águeda en la que se puede leer: "Se hizo esta Sn Águeda Vn Mt. a devoción Dn PROBO Juan Costilla. Año 1754". Se conservan en Villafáfila dos sillones barrocos con las efigies de San Froilán y San Atilano procedentes del Monasterio de Moreruela que fueron expuestas en el año 2001 en las Edades del Hombre en Zamora.

\footnotetext{
${ }^{21}$ C. Pérez Bragado. Villafáfila: Sus Iglesias Parroquiales, 1.996, Zamora.

${ }^{22}$ M. de la Granja, " El retablamento barroco de la Iglesia de Santa María del Moral de Villafáfila", Anuario. F. Ocampo, 1999, Zamora.
} 